\title{
Relation between crystal quality and fatigue life of a Cu-Al-Be single crystal shape memory alloy under repeated bending.
}

\author{
N. Siredey-Schwaller ${ }^{1 \mathrm{a}}$, A. Eberhardt ${ }^{1}$, E. Patoor ${ }^{2}$, P. Bastie $^{3,4}$ \\ ${ }^{1}$ Laboratoire de Physique et Mécanique des Matériaux, FRE CNRS 3236, ISGMP, Ecole Nationale d'Ingénieurs \\ de Metz, Ile du Saulcy, F- 57045 Metz cedex 01, France \\ ${ }^{2}$ Laboratoire de Physique et Mécanique des Matériaux, FRE CNRS 3236, ISGMP, ENSAM, 57 Metz cedex, \\ France \\ ${ }^{3}$ Laboratoire de Spectrométrie Physique, BP 87, 38402 Saint Martin d'Hères cedex, France \\ ${ }^{4}$ Institut Laue-Langevin, BP 156, 38042 Grenoble cedex 9, France
}

\begin{abstract}
The purpose of this study is to determine the parameters influencing the life of single crystalline $\mathrm{Cu}-\mathrm{Al}-\mathrm{Be}$ shape memory alloys. A strong correlation is found between crystal quality and fatigue life. For that purpose, a special device located at ILL (Institut laue-langevin) in Grenoble is employed. This device is a hard X-ray diffractometer using a transposition at high energy of the Guinier-Tennevin method.

Thanks to these X-ray studies, it is found that mechanical lifespan is very sensitive to crystalline quality. In presence of sub-grains (even if disorientation between subgrain is lower than $3^{\circ}$ ) or in presence of mosaïcity (distribution of the orientation of reticular planes around a mean value), the lifespan can be reduce by a factor of 10 .
\end{abstract}

\section{Material and Methods}

\subsection{Material}

The samples are single crystals whose composition is close to $\mathrm{Cu}-\mathrm{wt} .11 .4 \% \mathrm{Al}-\mathrm{wt} .0 .6 \% \mathrm{Be}$ and with a $\mathrm{Ms}$ temperature equal to $193 \mathrm{~K}$. They were heat-treated in order to reduce internal stresses, to minimize the vacancy concentration, while avoiding precipitates. Samples are wires of diameter $1.4 \mathrm{~mm}$ with the direction of $<001>$ $\mathrm{DO}_{3}$ lattice of austenite close to the direction of the wire within $\pm 5^{\circ}$ [1]. Two sets of samples with the same composition were cast in different furnaces: an industrial one (S1, Tréfimétaux) and a laboratory one (S6). Threshold stresses for martensitic transformation and hysteresis of the cycle in tensile test are checked to be nearly identical for the two castings.

\subsection{Repeated bending test}

The testing is carried out at room temperature, by imposing the maximum initial strain.. The apparatus allows a localization of the maximum strain near the middle of the wire, while fixations are in an undeformed part of the SMA wire. The frequency of the bending is $1 \mathrm{~Hz}$ which allows isothermal experimental conditions.

\subsection{Study of the crystalline quality}

The criteria used to characterize the crystalline quality are:

- Mosaicity value of the crystal (orientation distribution of a reticular plane family around its average value);

- Existence of sub-grains; determination of their respective positions in the wire (grains above each other in the wire length, denoted «bamboo» or side by side in the wire diameter, denoted « columnar»); determination of crystalline disorientation value.

A tool well suited for these measurements is the hard X-ray diffractometer, developed at the Institute Laue Langevin (ILL) [2]. It is only sensitive to the orientation of lattice planes; it provides bulk measurement, allows rapid analysis of large samples and gives information on the location of diffracting zones.

As Bragg angles are small (about 1 degree), the measurements are not sensitive to lattice parameter changes.

a email : nathalie.siredey@univ-metz.fr 


\section{Experimental set up}

\section{Principle}

The hard X-ray diffractometer of the Institute Laue Langevin (ILL) transposes to high energy a variant of the Laue method described by Guinier and Tennevin in 1949 [3]. This method is based on a property of focusing observed when Laue diagrams are recorded in transmission (fig. 1a). If the sample is a perfect crystal, the diagram is composed of lines corresponding to different excited reflections (fig. 1b). The Bragg angles are small (about 1 degree), the diffraction spots are located in the vicinity of the transmitted beam and can be considered as straight lines, as projection distortions are very low. Each point of the line is associated with a virtual slice of the sample. This slice is defined by the plane containing the generator focus, the point of the line and the normal to the diffracting planes. Any imperfection inducing disorientations of crystal disrupts the line.

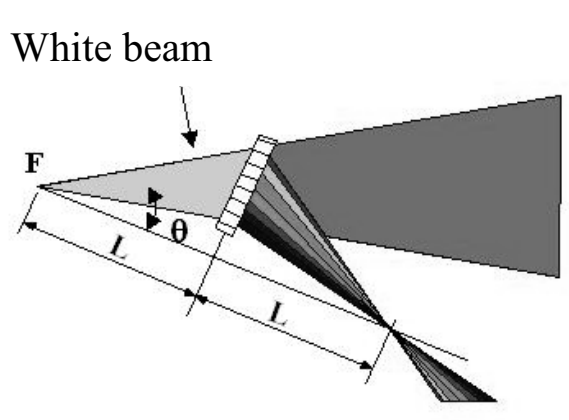

(a)

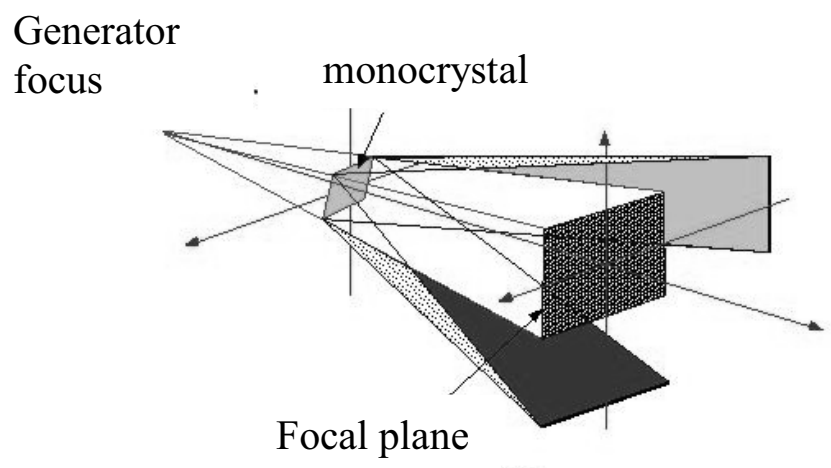

(b)

Fig. 1. (a) Principle of the focusing effect observed in Laue diagrams in transmission. (b) Schematic 3D diagram obtained for a perfect crystal.

Application to CuAlBe single crystal wires

The characterization of samples was obtained mainly from $\{00 \mathrm{~h}\}$ and $\{\mathrm{hh} 0\}$ reflections of the $\mathrm{DO}_{3}$ lattice. These reflections are used to separate information concerning rotations around crystal directions respectively perpendicular and parallel to the wire axis.

\section{Structural fatigue: numbers of cycles to failure}

The two castings present a noticeable difference in fatigue, as shown in Figure 2. Most samples of set S6 have a fatigue 10 times higher than samples of set $\mathrm{S} 1$.

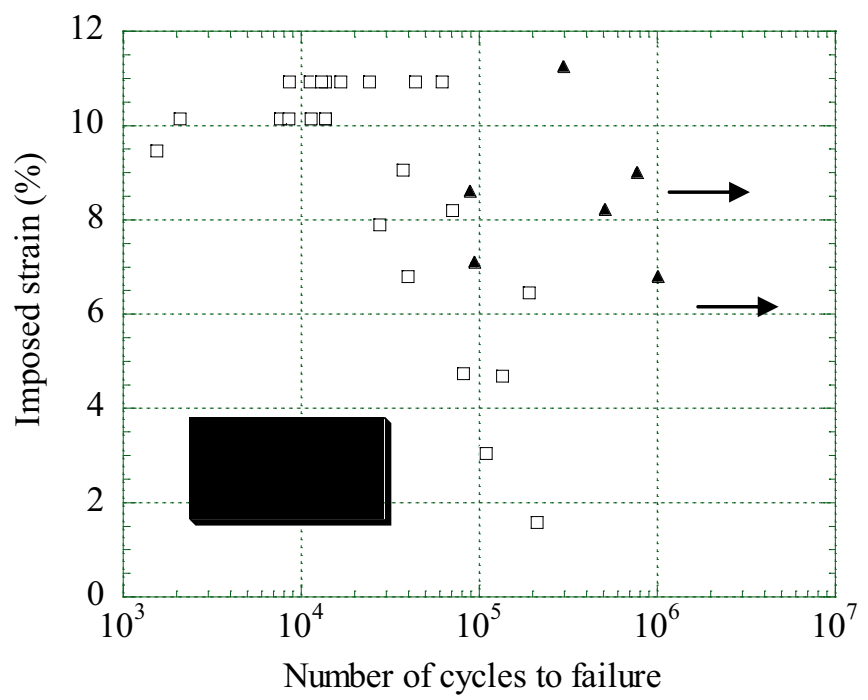

Fig. 2. Fatigue life during repeated bending of single crystal wires in $\mathrm{Cu}-\mathrm{Al}-\mathrm{Be}$. The composition is virtually identical. Sets $\mathrm{S} 1$ and $\mathrm{S} 6$ were cast in different furnaces. The arrows indicate a sample that has not broken. 
The study by hard x-rays diffractometry showed a significant difference between crystalline quality of samples of the two castings. The corresponding Laue diagrams for $\{00 \mathrm{~h}\}$ and $\{\mathrm{hh} 0\}$ reflections are plotted on Figure 3 .

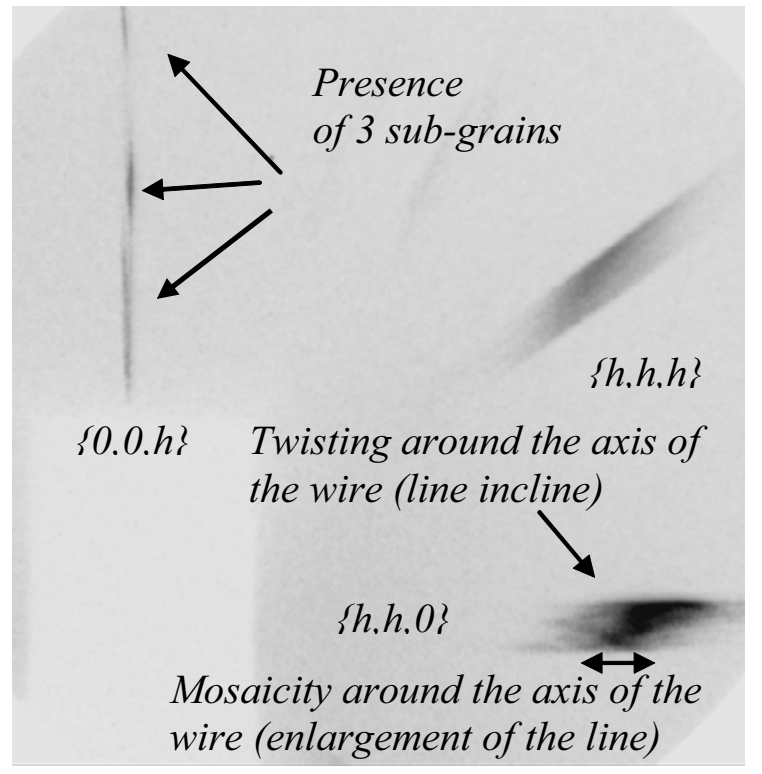

(a)

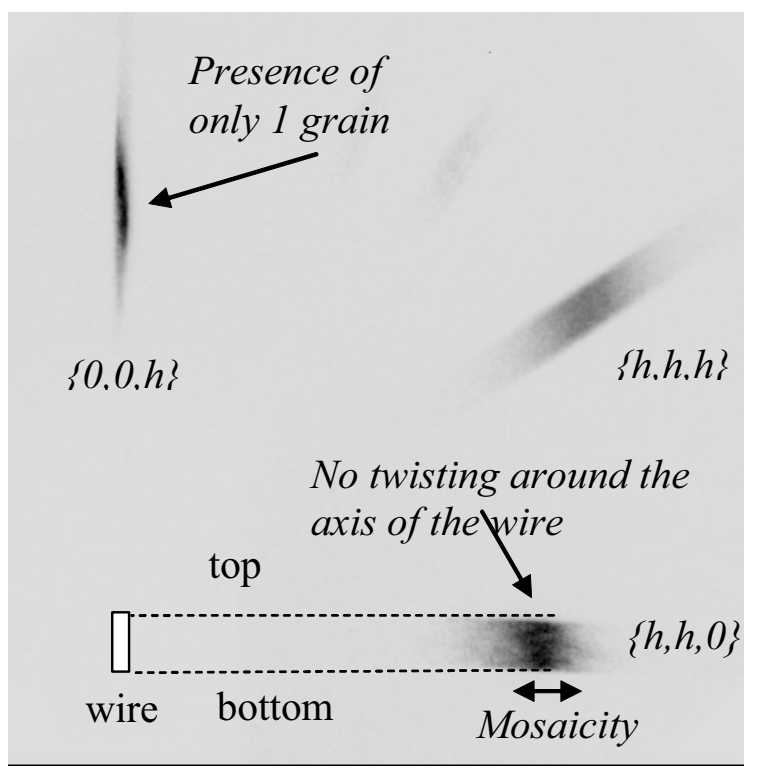

(b)

Fig. 3. Laue Diagrams of single crystal samples of Cu-Al-Be derived from: (a) the casting S1; (b) the casting S6. As already presented in figure 1, there is a direct correlation in one direction between the location on the wire and on the diffraction spot, as illustrated on (b) for the reflection $\{h, h, 0\}$ in the vertical direction.

Table 1 presents global mosaicity values for S6 samples, including disorientation between sub-grains when they exist.

Table 1. Crystalline quality of S6 samples related to their fatigue behaviour

\begin{tabular}{|c|c|c|c|c|}
\hline S6 samples & $\begin{array}{c}\text { Mosaicity } \\
\text { (min of arc) } \\
\text { on }\{\mathrm{hh} 0\} \text { spot }\end{array}$ & $\begin{array}{c}\text { Mosaicity } \\
\text { (min of arc) } \\
\text { on }\{00 \mathrm{~h}\} \text { spot }\end{array}$ & $\begin{array}{c}\text { Number of cycles } \\
\text { before failure }\end{array}$ & $\begin{array}{c}\text { Maximum } \\
\text { imposed strain }\end{array}$ \\
\hline S6A & $\begin{array}{c}\text { several grains } \\
\text { mosaic }(15 \text { to } 30) \\
\text { over } 2^{\circ}\end{array}$ & $\begin{array}{c}\text { several grains } \\
\text { mosaic }(18 \text { to } 40) \\
\text { over }>3^{\circ}\end{array}$ & $9.410^{4}$ & $7.1 \%$ \\
\hline S6B & 10 & 12 & More than $8.10^{5}$ & $9 \%$ \\
\hline S6C & 11 & 13 & More than $10^{6}$ & $6.8 \%$ \\
\hline S6D & 20 & 14 & $3.10^{5}$ & $11.25 \%$ \\
\hline S6E & 25 & 23 & $5.110^{5}$ & $8.2 \%$ \\
\hline S6F & $\begin{array}{c}\text { several grains } \\
\text { mosaic }(15 \text { to } 20) \\
\text { over } 3^{\circ}\end{array}$ & $\begin{array}{c}\text { several grains } \\
\text { mosaic }(12 \text { to 30) } \\
\text { over }>3^{\circ}\end{array}$ & $910^{4}$ & $8.6 \%$ \\
\hline
\end{tabular}

\section{Conclusion}

The heavy correlation observed between fatigue life and crystalline quality strongly suggests (or confirms [4,5]) that this parameter plays an important role and must be taken into account in studies of SMA single crystal.

From the previous measurements, it appears that hard X-rays diffractometry is a very well suited technique to characterize the crystalline perfection of SMA single crystal wires, providing a fast, bulk and topographic information. 
This study is extensively presented in the paper "Parameters influencing the fatigue life of a Cu-Al-Be single crystal shape memory alloy under repeated bending" - Smart Mat. and Struc. 18 (2009) 025014.

\section{References}

[1] Siredey-Schwaller N, Eberhardt A., Bastie P. 2009 Smart Mater. Struct. 18025014

[2] Hamelin B and Bastie P 1998 J. Physique 8 3-8

[3] Guinier A and Tennevin J 1949 Acta Crystallogr. 2 133-8

[4] Gil F X and Guilemany J M 1995 Rev. Metal. 31 222-7

[5] Siredey N, Hautcoeur A and Eberhardt A 2005 Mater. Sci. Eng. A 396 296-301 